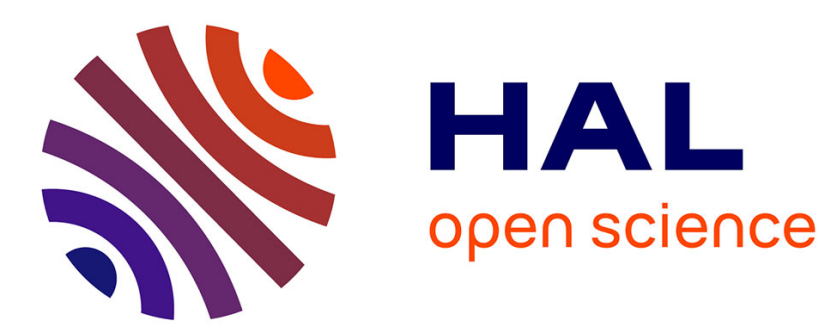

\title{
Longitudinal and seasonal structure of the ionospheric equatorial electric field
}

\author{
P. Alken, A. Chulliat, S. Maus
}

\section{To cite this version:}

P. Alken, A. Chulliat, S. Maus. Longitudinal and seasonal structure of the ionospheric equatorial electric field. Journal of Geophysical Research Space Physics, 2013, 118, pp.1298-1305. 10.1029/2012JA018314 . insu-03581803

\section{HAL Id: insu-03581803 https://hal-insu.archives-ouvertes.fr/insu-03581803}

Submitted on 20 Feb 2022

HAL is a multi-disciplinary open access archive for the deposit and dissemination of scientific research documents, whether they are published or not. The documents may come from teaching and research institutions in France or abroad, or from public or private research centers.
L'archive ouverte pluridisciplinaire HAL, est destinée au dépôt et à la diffusion de documents scientifiques de niveau recherche, publiés ou non, émanant des établissements d'enseignement et de recherche français ou étrangers, des laboratoires publics ou privés.

$$
\text { Copyright }
$$




\title{
Longitudinal and seasonal structure of the ionospheric equatorial electric field
}

\author{
P. Alken, ${ }^{1}$ A. Chulliat, ${ }^{2}$ and S. Maus ${ }^{1}$
}

Received 20 September 2012; revised 24 October 2012; accepted 15 November 2012; published 28 March 2013.

[1] The daytime eastward equatorial electric field (EEF) in the ionospheric E-region plays an important role in equatorial ionospheric dynamics. It is responsible for driving the equatorial electrojet (EEJ) current system, equatorial vertical ion drifts, and the equatorial ionization anomaly. Due to its importance, there is much interest in accurately measuring and modeling the EEF. In this work we propose a method of estimating the EEF using CHAMP satellite-derived latitudinal current profiles of the daytime EEJ along with $\Delta H$ measurements from ground magnetometer stations. Magnetometer station pairs in both Africa and South America were used for this study to produce time series of electrojet current profiles. These current profiles were then inverted for estimates of the EEF by solving the governing electrostatic equations. We compare our results with the Ion Velocity Meter (IVM) instrument on board the Communication/Navigation Outage Forecasting System satellite. We find high correlations of about $80 \%$ with the IVM data; however, we also find a constant offset of about $0.3 \mathrm{mV} / \mathrm{m}$ between the two data sets in Africa. Further investigation is needed to determine its cause. We compare the EEF structure in Africa and South America and find differences which can be attributed to the effect of atmospheric nonmigrating tides. This technique can be extended to any pair of ground magnetometer stations which can capture the day-to-day strength of the EEJ.

Citation: Alken, P., A. Chulliat, and S. Maus (2013), Longitudinal and seasonal structure of the ionospheric equatorial electric field, J. Geophys. Res. Space Physics, 118, 1298-1305, doi:10.1029/2012JA018314.

\section{Introduction}

[2] The neutral winds flowing in the ionosphere drive currents through collisions with the ionized particles. Since the wind field is typically divergent, a global electric field must build up to ensure that these currents are divergence-free. The eastward component of this electric field, called the $\mathrm{EEF}$, is particularly important at the equator, since it is responsible for driving the equatorial electrojet (EEJ) current system, the equatorial plasma fountain, and the equatorial ionization anomaly (EIA). This electric field is a fundamental parameter in any model describing equatorial ionospheric electrodynamics. However, direct measurements of the EEF have been restricted to a very few ground-based radars [Chau and Kudeki, 2006] and a small number of satellite missions [Fejer et al., 2008; de la Beaujardière and the C/NOFS Science Definition Team, 2004].

[3] Anderson et al. [2004] developed a method to infer ion drift velocities from $\Delta H$ measurements in Peru, using simultaneous measurements of the drift from a backscatter radar at the Jicamarca Radio Observatory. Their method is based on least squares regression and a neural network trained with

\footnotetext{
${ }^{1}$ National Geophysical Data Center, NOAA, Boulder, Colorado, USA.

${ }^{2}$ Institut de Physique du Globe de Paris, Paris, France.

Corresponding author: P. Alken, National Geophysical Data Center, NOAA E/GC1, 325 Broadway, Boulder, CO 80305-3328, USA. (patrick.alken@noaa.gov)

(C)2012. American Geophysical Union. All Rights Reserved. 2169-9380/13/2012JA018314
}

known inputs of $\Delta H$ and drift velocities to predict future drifts with only a $\Delta H$ input. While their method has been successfully used to predict E-region drift velocities, they need drift measurements to train the neural network, which are not readily available at other longitudes.

[4] Alken and Maus [2010b] developed a method to derive EEF estimates (and hence the ion drift velocities) at all longitudes, by modeling the EEJ current system using empirical inputs for the conductivities and wind field, and constraining the resulting current with magnetometer measurements from the CHAMP satellite to estimate the EEF. This method has the advantage of implicitly including longitudinal differences directly in the model, but does require satellite measurements to constrain the model. Since the CHAMP mission ended in 2010, this method cannot currently produce real-time EEF estimates, however the upcoming Swarm satellite mission will use this approach to model global EEF values in near real-time.

[5] Magnetometers flown on satellites offer very good spatial coverage of the geomagnetic field, but are unable to track temporal changes as well as ground-based magnetometers. Therefore, Alken and Maus [2010a] extended their previous EEF modeling method to work with ground-based $\Delta H$ measurements by using direct CHAMP overflights to produce a unit climatological EEJ latitudinal current profile, and using $\Delta H$ to determine the magnitude of the profile at any given time. They demonstrated this method on a pair of magnetometers in Peru and found excellent agreement with direct electric field measurements at Jicamarca. 


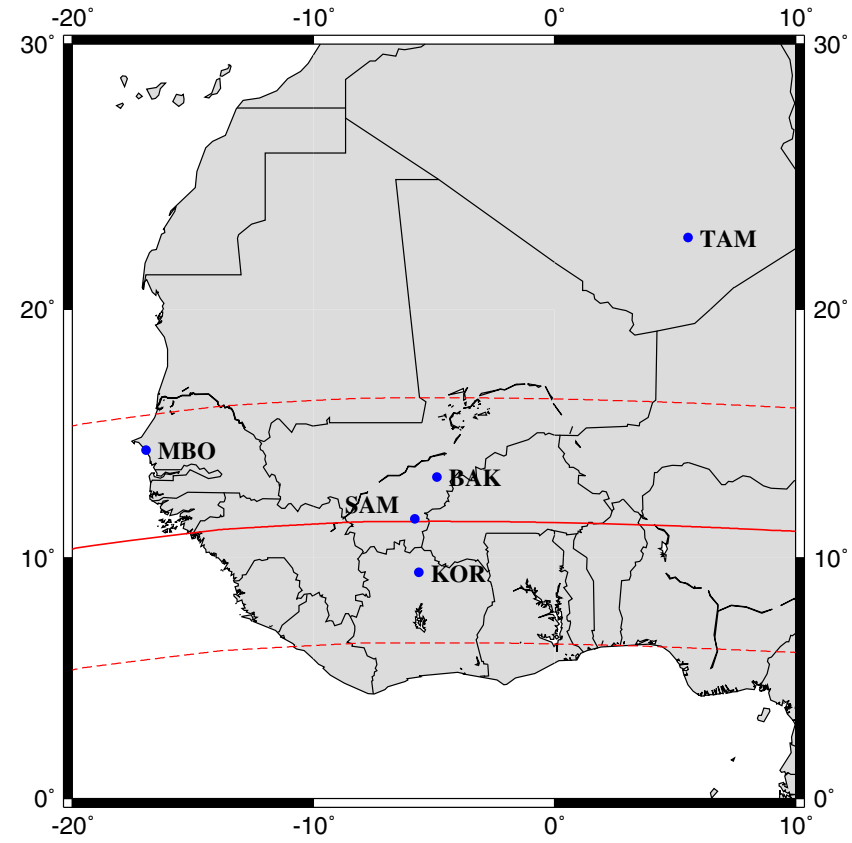

Figure 1. Locations of magnetometer stations in Africa used for this study. Solid red line indicates magnetic equator at $110 \mathrm{~km}$ altitude. Dashed red lines indicate $\pm 5^{\circ}$ from magnetic equator.

[6] In this study, we extend the method of Alken and Maus [2010a] to magnetometer stations in Africa, with the eventual goal to provide near real-time estimates of the EEF around the globe on a continuous temporal basis. This work represents the first time this method has been applied and validated outside the Peruvian longitude sector. We then analyze our data set of EEF estimates to study the longitudinal and seasonal variability of the ionosphere and the influence of global atmospheric tides on ionospheric dynamics, which has recently been shown to significantly impact equatorial ionospheric structure [Forbes et al., 2008; Lühr et al., 2008]. This method will also enable future analyses of the behavior of ionospheric dynamics during storms.

\section{Deriving a Time Series of EEJ Current Profiles From Ground Magnetometer Data}

[7] Lühr et al. [2004] present a method of deriving equatorial electrojet current flow from CHAMP satellite magnetometer measurements. CHAMP's near-polar orbit with an inclination of $87^{\circ}$ enabled it to record full latitudinal magnetic profiles of the daytime equatorial region for each orbit. To extract the equatorial electrojet current from the magnetic observations, they first subtracted a POMME geomagnetic field model [Maus et al., 2006], which removed the main, crustal, and magnetospheric field contributions. The remaining signal, which is primarily a combination of $S q$ and equatorial electrojet fields, was filtered to remove the midlatitude $S q$ contribution. This was done by modeling the $S q$ field by least squares fitting the midlatitude magnetic residuals to a magnetic field parametrization represented in a basis of spherical harmonics to degree 12 for the internal field and degree 2 for the external field. After subtracting this $S q$ field from the magnetic profiles, they were able to recover clean latitudinal magnetic signatures of the equatorial electrojet current. They took this a step further by calculating the actual EEJ current density by assuming a model of line currents flowing eastward at E-region altitudes, separated by regular intervals in latitude, and inverting the observed magnetic signal for the strength of these line currents. This procedure produced high-quality latitudinal profiles of the heightintegrated eastward current flow in the E-region. The full height profile of the current cannot be recovered with this method since CHAMP data alone are insufficient to constrain the altitude dependence.

[8] Using these height-integrated latitudinal current profiles of the EEJ, Alken and Maus [2010b] developed a method to estimate the eastward electric field driving the current system by solving the equations governing the current flow and constraining the solution with the observed CHAMP current. This method was then extended to make continuous time series of EEF estimates in Peru by constructing a unit climatological current profile from direct CHAMP overflights of a ground magnetic observatory near the dip equator and scaling the magnitude of the profile using the $\Delta H$ difference between the Jicamarca observatory on the dip equator and the Piura observatory with a dip latitude of $6.8^{\circ} \mathrm{N}$ [Alken and Maus, 2010a]. The $\Delta H$ signal between an observatory near the magnetic equator and another a few degrees away is known to correlate strongly with the equatorial electrojet current strength [Anderson et al., 2004]. The scaling was done by calculating a best fit linear relationship between $\Delta H$ observations and the peak current strength of individual CHAMP overflights. Using this linear relationship, individual $\Delta H$ measurements can be converted to current scaling factors to produce a complete time series of latitudinal current profiles $J_{\Delta H}(t, \theta)$.

[9] In the present work, we extend this methodology to a pair of magnetometer stations in Africa. In section 3 we discuss the magnetometer stations and their data processing used in this study. In section 4 we discuss our modeling framework including several significant improvements over the previous work of Alken and Maus [2010b]. In section 5 we validate our electric field estimates against observations from the Communication/Navigation Outage Forecasting System (C/NOFS) satellite mission. In section 6 we discuss the longitudinal and seasonal structure of the EEF.

\section{Magnetometer Station Data}

[10] For this study, we use data from WAMNET (West African Magnetometer Network) composed of three magnetometers: Samogossoni (SAM, $0.18^{\circ} \mathrm{N}$ dip latitude, $11.60^{\circ} \mathrm{N}$, $\left.5.77^{\circ} \mathrm{W}, 351 \mathrm{~m}\right)$, Bakarywéré (BAK, $1.59^{\circ} \mathrm{N}$ dip latitude, $13.30^{\circ} \mathrm{N}, 4.89^{\circ} \mathrm{W}, 279 \mathrm{~m}$ ), and Korhogo (KOR, 2.31 ${ }^{\circ} \mathrm{S}$ dip latitude, $\left.9.40^{\circ} \mathrm{N}, 5.63^{\circ} \mathrm{W}, 371 \mathrm{~m}\right)$. These magnetometers are all located near the dip equator and are shown in Figure 1. The Samogossoni and Bakarywéré stations were installed in 2006, and the Korhogo station was installed in 2009 at locations close to those of the Sikasso, San, and Korhogo stations of the International Electrojet Year experiment [Doumouya et al., 1998]. At each station, a fluxgate magnetometer records the three components of the geomagnetic field at a sampling rate of $1 \mathrm{~Hz}$. A thermally insulated hut filters out the diurnal temperature variations, which could otherwise generate artificial signals of up to a few nanotesla 


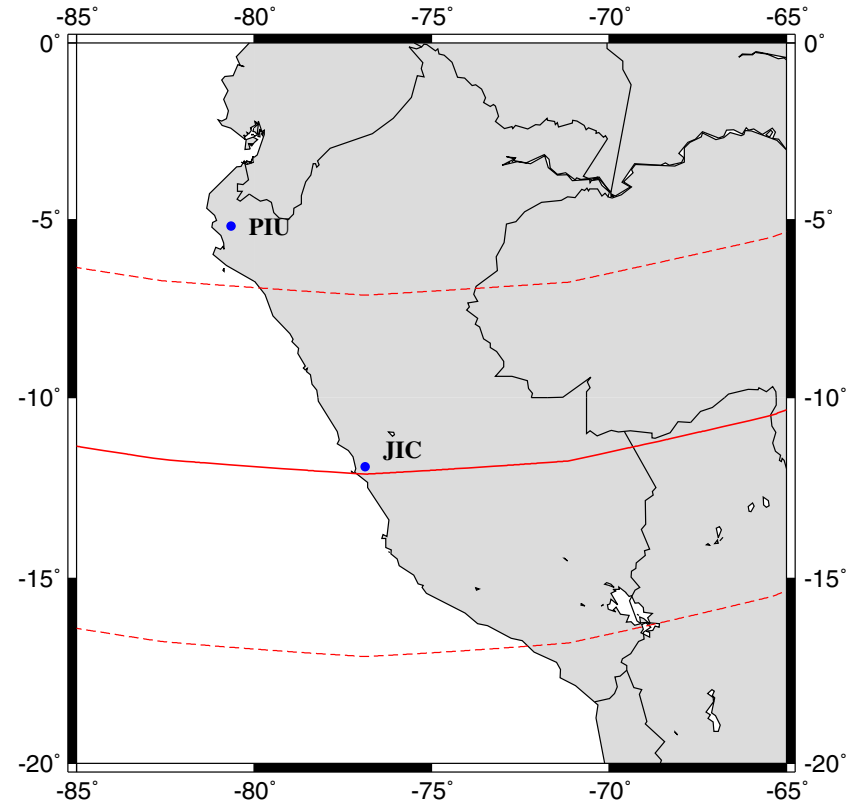

Figure 2. Locations of magnetometer stations in South America used for this study. Solid red line indicates magnetic equator at $110 \mathrm{~km}$ altitude. Dashed red lines indicate $\pm 5^{\circ}$ from magnetic equator.

at the same frequency as the equatorial electrojet signal. WAMNET data are available at www.bcmt.fr/WAMNET. In order to remove the effects of the $S q$ current system to obtain an electrojet signal, it is necessary to subtract simultaneous measurements of the horizontal field component using a magnetometer outside the EEJ region. We use data from the Tamanrasset (TAM, $11.35^{\circ} \mathrm{N}$ dip latitude, $\left.22.79^{\circ} \mathrm{N}, 5.53^{\circ} \mathrm{E}, 1373 \mathrm{~m}\right)$ and Mbour (MBO, $3.23^{\circ} \mathrm{N}$ dip latitude, $\left.14.39^{\circ} \mathrm{N}, 16.96^{\circ} \mathrm{W}, 7 \mathrm{~m}\right)$ INTERMAGNET observatories also shown in the figure. This difference in horizontal component, which we call $\Delta H$, has been shown to be a good proxy of the strength of the EEJ current [Rastogi and Klobuchar, 1990]. Before computing the $\Delta H$ between two magnetometer stations, we preprocessed the individual station data by fitting cubic splines to the nighttime (from 2200 to 0500 LT) horizontal component $(H)$ time series of hourly values, which were then subtracted from all the data. This effectively removed the main and crustal field baselines, typical quiet-day variations occurring in the magnetosphere, and possible instrument drift at the WAMNET stations (such drift is absent from definitive INTERMAGNET data). $\Delta H$ was then calculated by taking differences between the $H$ component residuals of the SAM station on the dip equator and both the TAM and MBO stations off of the dip equator. These differences were computed using the same UT, which could introduce some error due to the longitudinal differences between SAM and TAM/MBO (about $10^{\circ}$ separation). However, as described in section 2 , the $\Delta H$ values are used to construct a climatological latitudinal current profile which is then inverted for the EEF. This method relies on a strong correlation between $\Delta H$ and the peak EEJ current strength. Despite the longitudinal differences between SAM and $\mathrm{TAM} / \mathrm{MBO}$, we find high correlation between the $\Delta H$ signal and peak EEJ strength from direct CHAMP overflights at all local times, and so we have ignored possible errors arising from the local time differences between the stations. Furthermore, computing the $\Delta H$ signal at the same UT enables a more accurate representation of prompt penetration electric fields, which affect all stations at the same UT.

[11] In order to study longitudinal differences in the equatorial electric field, we also process data from two magnetic observatories in Peru. Data from Jicamarca (JIC, $0.60^{\circ} \mathrm{N}$ dip latitude, $\left.11.92^{\circ} \mathrm{S}, 76.87^{\circ} \mathrm{W}, 500 \mathrm{~m}\right)$ and Piura (PIU, $6.76^{\circ} \mathrm{N}$ dip latitude, $5.18^{\circ} \mathrm{S}, 80.64^{\circ} \mathrm{W}, 40 \mathrm{~m}$ ), whose locations are shown in Figure 2, are processed similarly to produce $\Delta H$ residuals tracking the strength of the equatorial electrojet.

\section{Modeling the Equatorial Electrojet Current}

[12] The currents and electric fields of the ionospheric equatorial region are governed by the equations

$$
\begin{gathered}
\nabla \times \mathbf{E}=0 \\
\mathbf{J}=\sigma(\mathbf{E}+\mathbf{u} \times \mathbf{B})
\end{gathered}
$$

where $\mathbf{E}$ is the electric field, $\mathbf{J}$ is the current density, $\sigma$ is the anisotropic conductivity tensor [Forbes, 1981, equation 10], $\mathbf{u}$ is the neutral wind velocity field, and $\mathbf{B}$ is the ambient geomagnetic field. In order to solve these equations, we assume that all longitudinal gradients vanish $(\partial / \partial \phi=0)$. This assumption is known to fail globally, particularly at the boundaries of the four-cell non-migrating ionospheric structure, where gradients in $\mathbf{E} \times \mathbf{B}$ drift velocities have been reported of up to $3 \mathrm{~m} / \mathrm{s} / \mathrm{deg}$ [Araujo-Pradere et al., 2011]. To fully account for these effects, we would need to solve the electrostatic equations in $3 \mathrm{D}$ which is beyond the scope of this paper. However, previous calculations of electric fields ignoring longitudinal gradients have demonstrated remarkable agreement with radar measurements at Jicamarca [Alken and Maus, 2010b]. This assumption, with the condition $\nabla \cdot \mathbf{J}=0$, allows the $J_{r}$ and $J_{\theta}$ components to be derived from a single current stream function $\psi$ :

$$
\begin{aligned}
& J_{r}=\frac{-1}{r^{2} \sin \theta} \frac{\partial \psi}{\partial \theta} \\
& J_{\theta}=\frac{1}{r \sin \theta} \frac{\partial \psi}{\partial r}
\end{aligned}
$$

[13] Equation (1) becomes

$$
\left.\begin{array}{c}
\partial_{r}\left(r E_{\theta}\right)-\partial_{\theta}\left(E_{r}\right)=0 \\
\partial_{\theta}\left(\sin \theta E_{\phi}\right)=0 \\
\partial_{r}\left(r E_{\phi}\right)=0
\end{array}\right\} \Rightarrow E_{\phi}=\frac{R E_{\phi_{0}}}{r \sin \theta}
$$

where $R$ is a constant of integration and can be taken as a reference radius, and $E_{\phi_{0}}$ is the eastward electric field at the equator at the radius $R$. Equation (6) shows that for a given value of the equatorial eastward electric field $E_{\phi_{0}}=$ $E_{\phi}(r=R, \theta=\pi / 2), E_{\phi}(r, \theta)$ is determined everywhere in the $(r, \theta)$ plane. The unknowns to be determined are therefore $E_{r}, E_{\theta}$, and $\psi$. We use empirical models to supply the conductivity $\sigma$, wind field $\mathbf{u}$, and geomagnetic field $\mathbf{B}$. The conductivity requires knowledge of the global densities and temperatures of the electrons, ions, and neutrals. For these we use the IRI-2012 [Bilitza et al., 2011] and NRLMSISE-00 [Picone et al., 2002] models. The equations for the direct, Pedersen, and Hall conductivities are 
given in Kelley [1989, appendix B]. The neutral wind field $\mathbf{u}$ is supplied by the horizontal wind model (HWM07) [Drob et al., 2008; Emmert et al., 2008]. HWM07 does not provide vertical wind velocities, and so they are ignored for this study. The geomagnetic field $\mathbf{B}$ is specified by the POMME-7 main field model [Maus et al., 2010].

[14] Eliminating $E_{r}$ and $E_{\theta}$ from equations (2)-(5) yields a second order partial differential equation for the current stream function $\psi$ :

$$
\begin{aligned}
& \alpha r \sigma_{r r} \partial_{r}^{2} \psi+\alpha \frac{\sigma_{\theta \theta}}{r} \partial_{\theta}^{2} \psi \\
& +\alpha\left(\sigma_{\theta r}+\sigma_{r \theta}\right) \partial_{r} \partial_{\theta} \psi \\
& +\left[\frac{\alpha}{r}\left(\sigma_{\theta r}+r^{2} \partial_{r} \frac{\sigma_{\theta r}}{r}+\partial_{\theta} \sigma_{\theta \theta}\right)-\sigma_{\theta r} \partial_{r} \alpha-\frac{\sigma_{\theta \theta}}{r} \partial_{\theta} \alpha\right] \partial_{\theta} \psi \\
& +\left[\alpha\left(\sigma_{r r}+r \partial_{r} \sigma_{r r}+\partial_{\theta} \sigma_{r \theta}\right)-r \sigma_{r r} \partial_{r} \alpha-\sigma_{r \theta} \partial_{\theta} \alpha\right] \partial_{r} \psi \\
& =r \beta \partial_{r} \alpha+\gamma \partial_{\theta} \alpha-\alpha\left(\beta+r \partial_{r} \beta+\partial_{\theta} \gamma\right)
\end{aligned}
$$

where

$$
\begin{gathered}
\alpha=r \sin \theta\left(\sigma_{r r} \sigma_{\theta \theta}-\sigma_{\theta r} \sigma_{r \theta}\right) \\
\beta=r \sin \theta\left(\sigma_{\theta r} \sigma_{r \phi}-\sigma_{r r} \sigma_{\theta \phi}\right) E_{\phi} \\
+r \sin \theta\left(\sigma_{\theta r}[\sigma(\mathbf{u} \times \mathbf{B})]_{r}-\sigma_{r r}[\sigma(\mathbf{u} \times \mathbf{B})]_{\theta}\right) \\
\gamma=r \sin \theta\left(\sigma_{\theta \theta} \sigma_{r \phi}-\sigma_{r \theta} \sigma_{\theta \phi}\right) E_{\phi} \\
+r \sin \theta\left(\sigma_{\theta \theta}[\sigma(\mathbf{u} \times \mathbf{B})]_{r}-\sigma_{r \theta}[\sigma(\mathbf{u} \times \mathbf{B})]_{\theta}\right)
\end{gathered}
$$

and the conductivity tensor $\sigma$ is represented in a basis of spherical coordinates. The coefficients of this equation differ from the previous work of Alken and Maus [2010b] by a constant factor in order to improve numerical stability at the lower boundary where the conductivity nearly vanishes.

[15] The terms $\beta$ and $\gamma$ depend on the eastward equatorial electric field $E_{\phi_{0}}$ which we are seeking through this modeling process. We therefore solve the partial differential equation (PDE) with a unit input of $E_{\phi_{0}}=1 \mathrm{mV} / \mathrm{m}$, compute the eastward current density $J_{\phi}$ from equation (2), using the solution $\psi$ to construct the full electric field $\mathbf{E}$, and then scale the height-integrated eastward current to provide the best match with the $\Delta H$-derived latitudinal current profile $J_{\Delta H}(\theta)$ (see section 2). This scaling factor then multiplies the unit input $E_{\phi_{0}}$ to give the true electric field value. Defining the height-integrated eastward current calculated from our model as

$$
J_{\mathrm{PDE}}(\theta)=\sum_{i} J_{\phi}\left(r_{i}, \theta\right) \delta r
$$

where $\delta r$ is the radial grid spacing, the scaling factor is computed from a least squares inversion of

$$
\begin{aligned}
J_{\Delta H}(\theta)= & s J_{\mathrm{PDE}}\left(\theta ; E_{\phi_{0}}=1 \mathrm{mV} / m, \mathbf{u}=0\right) \\
& +J_{\mathrm{PDE}}\left(\theta ; E_{\phi_{0}}=0, \mathbf{u}\right)-J_{\mathrm{DC}}
\end{aligned}
$$

[16] The PDE in equation (7) is solved twice, once with the eastward electric field turned off, and once with the winds turned off, since the solution is linear in the scaling factor $s$ only when $\mathbf{u}=0$. The final eastward equatorial electric field (EEF) is then $s \cdot(1 \mathrm{mV} / \mathrm{m}) . J_{\mathrm{DC}}$ is a constant DC offset to allow for a difference in zero levels between the modeled and observed current. The parameters $s$ and $J_{\mathrm{DC}}$ are determined by least-squares inversion of equation (12), under the constraint that the left and right hand sides of that equation must agree at the dip equator $(\theta=\pi / 2)$. This constraint has been found to yield more accurate electric fields [Alken and Maus, 2010b], since the EEF is primarily responsible for current structure near the dip equator, while the winds are primarily responsible for current structure at higher latitudes [Fambitakoye et al., 1976].

[17] The PDE in equation (7) is solved on a 2D grid in the $(r, \theta)$ plane, holding $\phi$ fixed at the longitude of the magnetometer station on the dip equator. The grid ranges from 65 to $500 \mathrm{~km}$ altitude in steps of $2.175 \mathrm{~km}$, and $-25^{\circ}$ to $25^{\circ}$ latitude in steps of $0.25^{\circ}$. The boundary conditions imposed on the PDE are that the current vanishes at the lower and upper boundaries $\left(\psi=0\right.$ at $r=r_{\min }$ and $\left.r_{\max }\right)$, and there is no radial current flow at the northern and southern boundaries $\left(\partial_{\theta} \psi=\right.$ 0 at $\theta=\theta_{\min }$ and $\left.\theta_{\max }\right)$. We solve the PDE using finite differencing on the 2D grid with a nine-cell stencil. Due to the fact that the conductivity along the geomagnetic field direction is orders of magnitude larger than the Pedersen and Hall conductivities, the finite difference matrix is ill conditioned and special care must be taken to precondition the matrix prior to solving the linear system. We use a more sophisticated pre-conditioner than our previous work which allows nearly all $\Delta H$ observations to be successfully processed to produce EEF values.

\section{Comparison with $\mathrm{C} / \mathrm{NOFS}$}

[18] To validate our electric field estimates, we use the ion velocity meter (IVM) instrument, part of the coupled ion neutral dynamics investigation (CINDI) payload on board the Communication/Navigation Outage Forecasting System (C/NOFS) satellite [de la Beaujardière and the C/NOFS Science Definition Team, 2004]. C/NOFS was launched in April 2008 into a low Earth orbit ranging from about 400 to $850 \mathrm{~km}$ altitude, and an inclination of $13^{\circ}$. The IVM instrument measures cross-track $\mathbf{E} \times \mathbf{B}$ ion drift velocities with an accuracy of $2 \mathrm{~m} / \mathrm{s}$ and a sensitivity of $1 \mathrm{~m} / \mathrm{s}$ and along-track drift velocities with an accuracy of $10 \mathrm{~m} / \mathrm{s}$ and sensitivity of $5 \mathrm{~m} / \mathrm{s}$. The observed ion drifts can be converted to electric fields with the well-known relation $\mathbf{E}=-\mathbf{v} \times \mathbf{B}$. We use the International Geomagnetic Reference Field (IGRF) model [Finlay et al., 2010] to transform the IVM drift measurements into electric field values. Some processing was performed on the IVM measurements prior to comparison. First, we compute $1 \mathrm{~min}$ averages to smooth out very short timescale features. Second, we discard data recorded over $500 \mathrm{~km}$ altitude, since the instrument tends to have higher accuracy at lower altitudes when measuring heavier ions, such as $\mathrm{O}^{+}$[Araujo-Pradere et al., 2011].

[19] In order to gain an understanding of the accuracy of the IVM measurements as a proxy for E-region electric fields, we first compare them with electric field measurements from the JULIA radar located at the Jicamarca Radio Observatory near Lima, Peru. JULIA (Jicamarca Unattended Long-term Investigations of the Ionosphere and Atmosphere) uses a coherent scatter radar to accurately measure the drift velocities of plasma irregularities near $150 \mathrm{~km}$ altitude [Chau and Kudeki, 2006]. We convert these drift velocities to electric field values using the IGRF and compare the eastward electric field component with simultaneous IVM measurements during C/NOFS overflights of Jicamarca. We define a simultaneous measurement when $\mathrm{C} / \mathrm{NOFS}$ 

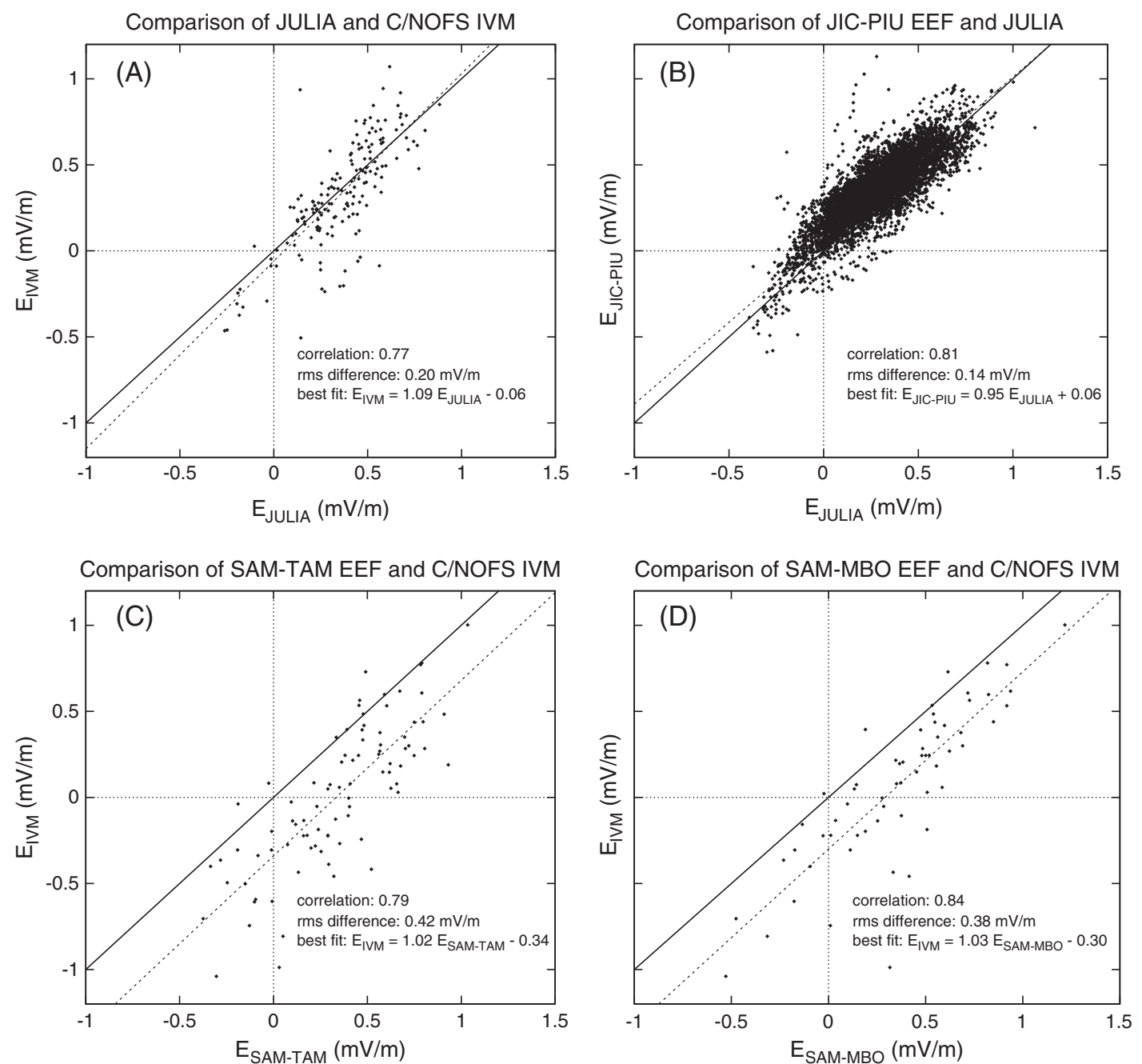

Figure 3. Comparison of (A) JULIA radar and C/NOFS IVM electric field measurements, (B) JULIA radar and JIC-PIU $\Delta H$-derived electric fields, (C) C/NOFS IVM and SAM-TAM $\Delta H$-derived electric fields, and (D) C/NOFS IVM and SAM-MBO $\Delta H$-derived electric fields. The $y=x$ line is solid, best fit line is dashed.

passes within $\pm 3^{\circ}$ latitude and $\pm 3^{\circ}$ longitude of Jicamarca and when the two instruments have recorded data within 10 min of each other.

[20] In Figure 3A, we plot the simultaneous eastward electric field measurements from the C/NOFS IVM and JULIA radar instruments. We found 169 simultaneous measurement events using all available CINDI data from January 2009 to June 2012. We find a high correlation of $77 \%$ and a low root mean square (RMS) difference of $0.20 \mathrm{mV} / \mathrm{m}$. The best fit line nearly demonstrates a 1-to- 1 correspondence, with a slope of 1.09 and intercept of $-0.06 \mathrm{mV} / \mathrm{m}$. Previous studies have shown the existence of altitude gradients in the zonal electric field [Abdu et al., 2009; Pingree and Fejer, 1987], which could explain some of the scatter in the figure, since the JULIA measurements are taken at $150 \mathrm{~km}$, while we use $\mathrm{C} / \mathrm{NOFS}$ data between 400 and $500 \mathrm{~km}$ altitude. But in general, this result indicates the C/NOFS IVM measurements are a good proxy for E-region electric fields. In Figure 3B, we plot the simultaneous measurements from the JULIA radar and $\Delta H$-derived electric fields from the Jicamarca and Piura observatories. We found 6512 simultaneous measurements using all available data from October 2000 to August 2012. We find a correlation of $81 \%$ and a low RMS difference of $0.14 \mathrm{mV} / \mathrm{m}$. Stolle et al. [2008] found a similar correlation between JULIA vertical drift and $\Delta H$ measurements from the Huancayo and Piura observatories. The best fit line has a slope of 0.95 and intercept of $0.06 \mathrm{mV} / \mathrm{m}$. In Figure 3C, we plot simultaneous measurements from the C/NOFS IVM and $\Delta H$-derived electric fields from the SAM and TAM magnetometer stations in Africa. We use the same criteria to define a simultaneous measurement for C/NOFS overflights of the SAM station as for JULIA. We again find a high correlation of $79 \%$ and a slope of 1.02 in the best fit line; however, we find a significant constant offset of $0.34 \mathrm{mV} / \mathrm{m}$ between the C/NOFS and $\Delta H$ electric fields. This offset could be due to (1) uncertainties in the calibration of the IVM instrument, (2) errors in our EEF modeling in the African sector, or (3) errors in removing the baseline from the $\Delta H$ measurements. Finally, in Figure 3D, we plot the C/NOFS IVM observations against the $\Delta H$-derived electric fields from the SAM and MBO stations. We find similar 
Table 1. Mean of residuals after subtracting EEFM model in units of $\mathrm{mV} / \mathrm{m}$.

\begin{tabular}{lc}
\hline Residuals & Mean of residuals $(\mathrm{mV} / \mathrm{m})$ \\
\hline$E_{J U L I A}-E E F M$ & -0.004 \\
$E_{J I C-P I U}-E E F M$ & -0.024 \\
$E_{S A M-T A M}-E E F M$ & 0.003 \\
$E_{S A M-M B O}-E E F M$ & -0.029 \\
$E_{I V M}-E E F M$ (at Jicamarca) & -0.040 \\
$E_{I V M}-E E F M$ (for SAM-TAM) & $-\mathbf{0 . 3 4 5}$ \\
$E_{I V M}-E E F M$ (for SAM-MBO) & $-\mathbf{0 . 3 1 6}$ \\
\hline
\end{tabular}

statistics to the SAM-TAM data, with a correlation of $84 \%$ and a best fit line with a slope of 1.03 and a constant offset of $-0.30 \mathrm{mV} / \mathrm{m}$.

[21] To further investigate this offset, we subtracted the EEFM model [Alken, 2009] from the JULIA and C/NOFS electric field measurements, and the $\Delta H$-derived electric field estimates. EEFM is a global model of the climatological mean of the EEF derived from the CHAMP database using the same modeling approach described in section 4 . We subtracted EEFM from the electric field data, using the same time, longitude, season, and solar flux level as the measurement, and computed means of the resulting residuals, which are summarized in Table 1 . For the $\Delta H$-derived values, the longitude of the station near the dip equator was used to compute the EEFM value.

[22] If the EEFM model represents an accurate estimate of the EEF climatological mean, we would expect the mean of the residuals to be nearly 0 . This is indeed the case for all residuals except for $E_{\mathrm{IVM}}-E E F M$, which have means of -0.345 and $-0.316 \mathrm{mV} / \mathrm{m}$ for simultaneous C/NOFS measurements with the SAM-TAM and SAM-MBO data sets, respectively. We can conclude from this table that possibility (3), errors in the $\Delta H$ baselines, is not the cause of the offset, since these residuals have nearly 0 means. However, since the EEFM model was constructed using a similar modeling method used for the $E_{\Delta H}$ values, we cannot determine whether the C/NOFS IVM data or the EEF modeling method is responsible for the constant offset in the African sector. Further investigation will be needed to determine its cause.

\section{Discussion}

[23] The eastward electric field data sets from the different magnetometer station pairs are shown in Figure 4 along with the corresponding output from the EEFM model. The plots are shown as functions of local time and season, and the EEFM model was run for each of the $\Delta H$-derived EEF values using the local time, season, and solar flux value at the time of the measurement. We find very good general agreement between the data and model, with RMS differences of $0.27 \mathrm{mV} / \mathrm{m}$ for JIC-PIU, $0.28 \mathrm{mV} / \mathrm{m}$ for SAMTAM, and $0.26 \mathrm{mV} / \mathrm{m}$ for SAM-MBO. There are small scale differences in the seasonal structure between the $\Delta H$ derived electric field estimates and the EEFM model. EEFM was parametrized to capture the seasonal differences between spring/fall and summer/winter, but does not capture smaller scale features due to changes in the wind field, or the high day-to-day variability of the EEF. In all cases we see stronger electric fields around March and September equinox, which is consistent with many previous studies [Tarpley, 1973; Alken and Maus, 2007; Pedatella et al.,
2011] and is primarily due to the Sun's direct position over the geographic equator.

[24] Interestingly, we find that the EEF in the west-African sector is consistently stronger than in western South America for all seasons and local times. Fejer et al. [2008] report similar features in the quiet time vertical drift velocities measured by the ionospheric plasma and electrodynamics probe instrument on board the ROCSAT-1 satellite. Since the EEF is primarily responsible for driving vertical drift in the F-region, we would expect similar seasonal and longitudinal structure. The longitudinal structure of the EEF can be influenced by longitudinal variations in the conductivity, the geomagnetic field, and the neutral winds. Previous studies have attributed longitudinal variations in low and midlatitude current systems to the geomagnetic field [Matsushita and Maeda, 1965; Stening, 1977]. However, the effect of an enhanced geomagnetic field would reduce the conductivity in the region, and since the low-latitude wind-driven currents are governed by the term $\sigma(\mathbf{u} \times \mathbf{B})$, the reduced conductivity would tend to offset the larger geomagnetic field. While we anticipate this effect on the longitudinal variations of the EEF would be small, we would need to apply our model to more than the two magnetometer chains in this study to determine the extent to which conductivity and geomagnetic field variations affect the EEF structure.

[25] The other possibility is the longitudinal variations in the neutral wind field, since the global wind dynamo creates and maintains the equatorial electric field. Recently, it has been found that global diurnal and semidiurnal tides, driven by latent heat release in deep convective tropical clouds, can propagate vertically to ionospheric altitudes, achieving wind amplitudes which can significantly modulate the polarization electric field in the E-region. This electric field drives the equatorial electrojet current, as well as vertical ion drift, and so the effects of the tides are found in nearly all ionospheric parameters.

[26] For most of the year, the strongest tidal harmonic found in equatorial ionospheric structure is DE3, the eastward propagating diurnal tide with zonal wavenumber 3 [Forbes et al., 2008; Lühr et al., 2012]. DE3 "wave-4" structure has been found in many ionospheric data sets, including the EEF, equatorial electrojet current, and vertical ion drift velocities [Immel et al., 2006; England et al., 2006; Alken and Maus, 2007; Lühr et al., 2008; Fejer et al., 2008; Alken and Maus, 2010b]. The wave-4 structure typically contains maxima over both Africa and South America. While DE3 persists for most of the year, during the winter months the amplitude of the DE2 harmonic dominates, leading to a "wave-3" longitudinal structure [Forbes et al., 2008; Lühr et al., 2012]. This wave-3 structure effectively eliminates the crest over South America but leaves the maximum over Africa intact. This is confirmed in Figure 4 where the JICPIU plots show a diminished EEF signal from December through February, while the SAM-TAM and SAM-MBO plots show significant amplitude during these months.

\section{Conclusion}

[27] In this work, we have calculated eastward electric field values using $\Delta H$ measurements from ground magnetometer stations in Africa and South America. The numerical stability of our EEF modeling approach has been improved 

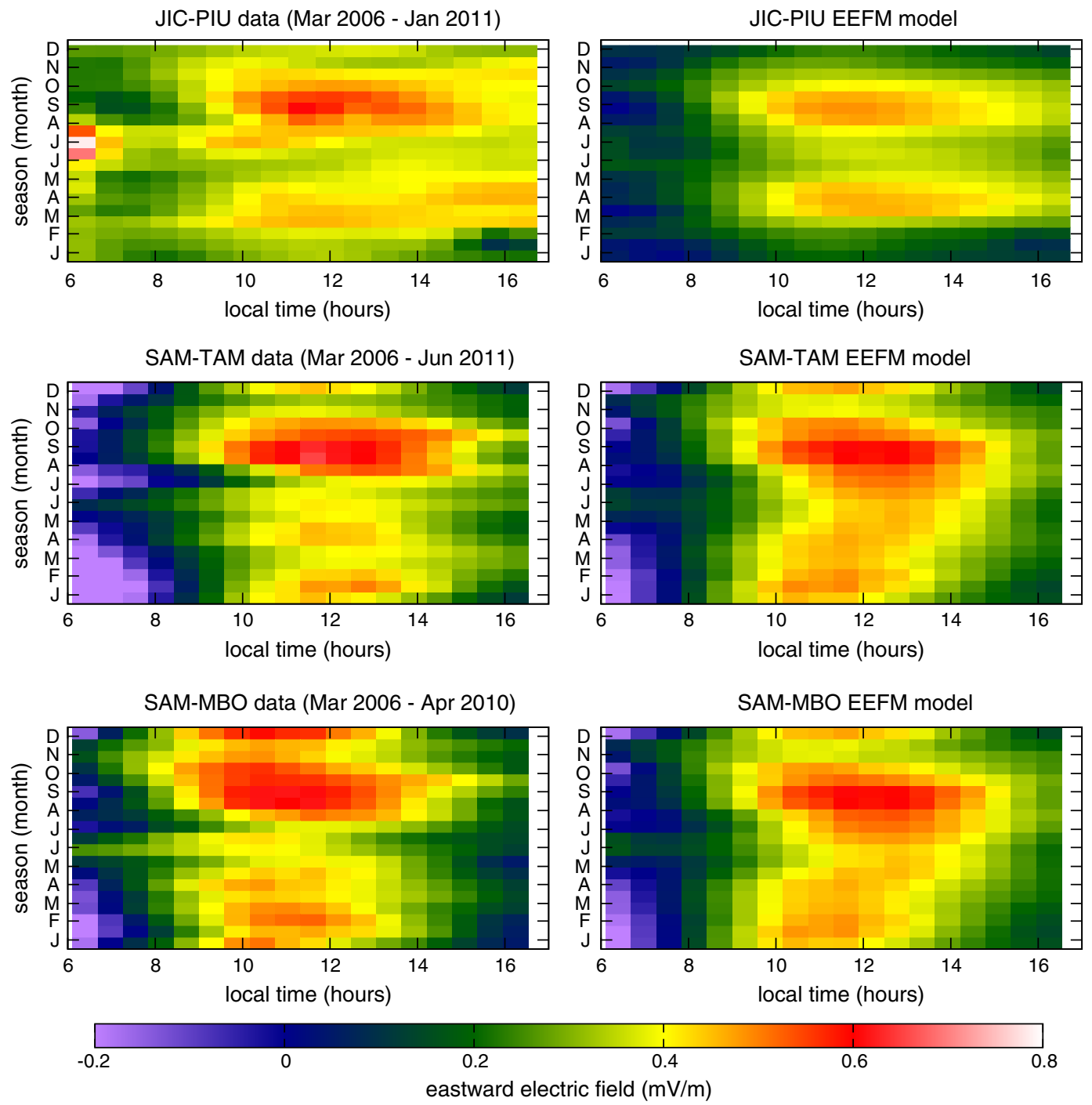

Figure 4. Eastward electric field estimates (top row) computed from Jicamarca and Piura magnetometer stations (left) along with corresponding EEFM model output (right). Eastward electric field estimates (middle row) computed from Samogossoni and Tamanrasset magnetometer stations (left) along with corresponding EEFM model output (right). Eastward electric field estimates (bottom row) computed from Samogossoni and Mbour magnetometer stations (left) along with corresponding EEFM model output (right). All plots are averaged over the time intervals shown.

by modifying the electrostatic equation coefficients to better handle vanishing conductivities as well as using a better preconditioner for the finite difference matrix solver. Our EEF estimates in the African sector are highly correlated with C/NOFS overflights (about $80 \%$ ), but we found a constant offset of about $0.3 \mathrm{mV} / \mathrm{m}$ between the two data sets, which is not present in South America. We showed that this offset cannot be due to the $\Delta H$ observations, and so it must be due to either uncertainties in the calibration of the C/NOFS IVM instrument or errors in the empirical models used to solve the electrostatic equation. The upcoming Swarm satellite mission offers the best opportunity to identify the origin of this offset, since these satellites will carry electric field instruments which can be directly compared with $\mathrm{C} / \mathrm{NOFS}$ data and our modeled estimates. The seasonal and longitudinal behavior of the EEF can be explained in large part as effects of atmospheric tidal structure. The magnitude of the
EEF is consistently stronger in Africa than in South America at all local times and seasons, which we attribute to atmospheric non-migrating tides, of which DE3 dominates for most of the year. During winter, the effect of the DE2 tide is readily apparent with a significantly diminished EEF strength over South America. The EEF data also exhibit maxima during both equinoxes (although stronger during fall) over both continents.

[28] The methods in this study can be applied to any equatorial magnetometer station pair around the globe, providing new avenues to study the longitudinal and seasonal structure of the equatorial ionosphere. Since the EEF is among the most fundamental parameters in the equatorial ionosphere, this work will also allow the study of low-latitude current systems and ion drift, both of which are driven by the EEF.

[29] Acknowledgments. The CINDI data are provided through the auspices of the CINDI team at the University of Texas at Dallas supported 
by NASA grant NAS5-01068. The WAMNET magnetometer network is funded by the Centre National d'Etudes Spatiales (CNES), and is maintained by the Institut de Physique du Globe de Paris (IPGP). The operational support of the CHAMP mission by the German Aerospace Center (DLR) is gratefully acknowledged. The Jicamarca Radio Observatory is a facility of the Instituto Geofisico del Peru operated with support from the NSF through Cornell University. This is IPGP contribution number 3348.

\section{References}

Abdu, M. A., et al. (2009), Conjugate Point Equatorial Experiment (COPEX) campaign in Brazil: Electrodynamics highlights on spread $F$ development conditions and day-to-day variability, J. Geophys. Res., 114, A04308, doi:10.1029/2008JA013749.

Alken, P. (2009), Equatorial electric field model (EEFM), http://geomag. org/models/EEF.html, manuscript in preparation.

Alken, P., and S. Maus (2007), Spatio-temporal characterization of the equatorial electrojet from CHAMP, Ørsted, and SAC-C satellite magnetic measurements, J. Geophys. Res., 112, doi:10.1029/2007JA012524.

Alken, P., and S. Maus (2010a), Relationship between the ionospheric eastward electric field and the equatorial electrojet, Geophys. Res. Lett., 37, L04104, doi:10.1029/2009GL041989.

Alken, P., and S. Maus (2010b), Electric fields in the equatorial ionosphere derived from CHAMP satellite magnetic field measurements, J. Atmos. Sol. Terr. Phys., 72, 319-326, doi:10.1016/j.jastp.2009.02.006.

Anderson, D., A. Anghel, J. Chau, and O. Veliz (2004), Daytime vertical $\mathrm{E} \times \mathrm{B}$ drift velocities inferred from ground-based magnetometer observations at low latitudes, Space Weather, 2, S11001, doi:10.1029/ 2004SW000095.

Araujo-Pradere, E. A., D. N. Anderson, and M. Fedrizzi (2011), Communications/Navigation Outage Forecasting System observational support for the equatorial $\mathrm{E} \times \mathrm{B}$ drift velocities associated with the four-cell tidal structures, Radio Sci., 46, RS0D09, doi:10.1029/2010RS004557.

Bilitza, D., L.-A. McKinnell, B. Reinisch, and T. Fuller-Rowell (2011), The International Reference Ionosphere (IRI) today and in the future, J. Geodesy, 85, 909-920, doi:10.1007/s00190-010-0427-x.

Chau, J. L., and E. Kudeki (2006), Statistics of $150 \mathrm{~km}$ echoes over Jicamarca based on low-power VHF observations, Ann. Geophys., 24, 1305-1310.

de la Beaujardière, O., and the C/NOFS Science Definition Team (2004), C/NOFS: A mission to forecast scintillations, J. Atmos. Sol. Terr. Phys., 66(17), 1573-1591, doi:10.1016/j.jastp.2004.07.030.

Doumouya, V., J. Vassal, Y. Cohen, O. Fambitakoye, and M. Menvielle (1998), The equatorial electrojet at African longitudes: First results from magnetic measurements, Annales de Geophysicae, 16, 658-676.

Drob, D. P., et al. (2008), An empirical model of the Earth's horizontal wind fields: HWM07, J. Geophys. Res., 113, A12304, doi:10.1029/ 2008JA013668.

Emmert, J. T., D. P. Drob, G. G. Shepherd, G. Hernandez, M. J. Jarvis, J. W. Meriwether, R. J. Niciejewski, D. P. Sipler, and C. A. Tepley (2008), DWM07 global empirical model of upper thermospheric storm-induced disturbance winds, J. Geophys. Res., 113, A11319, doi:10.1029/2008JA013541.

England, S. L., S. Maus, T. J. Immel, and S. B. Mende (2006), Longitudinal variation of the E-region electric fields caused by atmospheric tides, Geophys. Res. Lett., 33.

Fambitakoye, O., P. N. Mayaud, and A. D. Richmond (1976), The equatorial electrojet and regular daily variation $S_{R}$ :-III. Comparison of observations with a physical model, J. Atmos. Terr. Phys., 38, 113-121.
Fejer, B. G., J. W. Jensen, and S.-Y. Su (2008), Quiet-time equatorial $F$ region vertical plasma drift model derived from ROCSAT-1 observations, J. Geophys. Res., 113, A05304, doi:10.1029/2007JA012801.

Finlay, C. C., et al. (2010), International Geomagnetic Reference Field: The eleventh generation, Geophys. J. Int., 183, 1216-1230, doi:10.1111/ j.1365-246X.2010.04804.x, Issue 3.

Forbes, J. M. (1981), The equatorial electrojet, Rev. Geophys. Space Phys., 19(3), 469-504.

Forbes, J. M., X. Zhang, S. Palo, J. Russell, C. J. Mertens, and M. Mlynczak (2008), Tidal variability in the ionospheric dynamo region, J. Geophys. Res., 113, A02310, doi:10.1029/2007JA012737.

Immel, T. J., E. Sagawa, S. L. England, S. B. Henderson, M. E. Hagan, S. B. Mende, H. U. Frey, C. M. Swenson, and L. J. Paxton (2006), Control of equatorial ionospheric morphology by atmospheric tides, Geophys. Res. Lett., 33, L15108, doi:10.1029/2006GL026161.

Kelley, M. C. (1989), The Earth's Ionosphere: Plasma Physics and Electrodynamics, Academic Press Inc, San Diego.

Lühr, H., S. Maus, and M. Rother (2004), Noon-time equatorial electrojet: Its spatial features as determined by the CHAMP satellite, J. Geophys. Res., 109, A01306, doi:10.1029/2002JA009656.

Lühr, H., M. Rother, K. Häusler, P. Alken, and S. Maus (2008), The influence of non-migrating tides on the longitudinal variation of the equatorial electrojet, J. Geophys. Res., 113, A08313, doi:10.1029/2008JA013064.

Lühr, H., M. Rother, K. Häusler, B. Fejer, and P. Alken (2012), Direct comparison of non-migrating tidal signatures in the electrojet, vertical plasma drift and equatorial ionization anomaly, J. Atmos. Sol. Terr. Phys., 75-76, 31-43, doi:10.1016/j.jastp.2011.07.009.

Matsushita, S., and H. Maeda (1965), On the geomagnetic solar quiet daily variation field during the IGY, J. Geophys. Res., 70(11), 2535-2558.

Maus, S., M. Rother, C. Stolle, W. Mai, S. Choi, H. Lühr, D. Cooke, and C. Roth (2006), Third generation of the Potsdam Magnetic Model of the Earth (POMME), Geochem. Geophys. Geosyst., 7, doi:10.1029/ $2006 \mathrm{GC} 001269$.

Maus, S., C. Manoj, J. Rauberg, I. Michaelis, and H. Lühr (2010), NOAA/ NGDC candidate models for the 11th generation International Geomagnetic Reference Field and the concurrent release of the 6th generation POMME magnetic model, Earth Planets Space, 62, 729-735.

Pedatella, N. M., J. M. Forbes, and A. D. Richmond (2011), Seasonal and longitudinal variations of the solar quiet $(S q)$ current system during solar minimum determined by CHAMP satellite magnetic field observations, J. Geophys. Res., 116, A04317, doi:10.1029/2010JA016289.

Picone, J. M., A. E. Hedin, D. P. Drob, and A. C. Aikin (2002), NRLMSISE00 empirical model of the atmosphere: Statistical comparisons and scientific issues, J. Geophys. Res., 107, doi:10.1029/2002JA009430.

Pingree, J. E., and B. G. Fejer (1987), On the height variation of the equatorial $F$ region vertical plasma drift, J. Geophys. Res., 92(A5), 4763-4766.

Rastogi, R. G., and J. A. Klobuchar (1990), Ionospheric electron content within the equatorial F2 layer anomaly belt, J. Geophys. Res., 95(A11), $19,045-19,052$

Stening, R. J. (1977), Field-aligned currents driven by the ionospheric dynamo, J. Atmos. Terr. Phys., 39, 933-937.

Stolle, C., C. Manoj, H. Lühr, S. Maus, and P. Alken (2008), Estimating the day time equatorial ionization anomaly strength from electric field proxies, J. Geophys. Res., 113, A09310, doi:10.1029/2007JA012781.

Tarpley, J. D. (1973), Seasonal movement of the $S q$ current foci and related effects in the equatorial electrojet, J. Atmos. Terr. Phys., 35, 1063-1071. 